\title{
Protective and Toxic Neuroinflammation in Amyotrophic Lateral Sclerosis
}

\author{
Kristopher G. Hooten • David R. Beers • Weihua Zhao • \\ Stanley H. Appel
}

Published online: 8 January 2015

(C) The American Society for Experimental NeuroTherapeutics, Inc. 2015

\begin{abstract}
Amyotrophic lateral sclerosis (ALS) is a clinically heterogeneous disorder characterized by loss of motor neurons, resulting in paralysis and death. Multiple mechanisms of motor neuron injury have been implicated based upon the more than 20 different genetic causes of familial ALS. These inherited mutations compromise diverse motor neuron pathways leading to cell-autonomous injury. In the ALS transgenic mouse models, however, motor neurons do not die alone. Cell death is noncell-autonomous dependent upon a well orchestrated dialogue between motor neurons and surrounding glia and adaptive immune cells. The pathogenesis of ALS consists of 2 stages: an early neuroprotective stage and a later neurotoxic stage. During early phases of disease progression, the immune system is protective with glia and T cells, especially M2 macrophages/microglia, and T helper 2 cells and regulatory $\mathrm{T}$ cells, providing anti-inflammatory factors that sustain motor neuron viability. As the disease progresses and motor neuron injury accelerates, a second rapidly progressing phase develops, characterized by M1 macrophages/microglia, and proinflammatory $\mathrm{T}$ cells. In rapidly progressing ALS patients, as in transgenic mice, neuroprotective regulatory $\mathrm{T}$ cells are significantly decreased and neurotoxicity predominates. Our
\end{abstract}

K.G.H. and D.R.B. contributed equally to this manuscript.

Electronic supplementary material The online version of this article (doi:10.1007/s13311-014-0329-3) contains supplementary material, which is available to authorized users.

K. G. Hooten • D. R. Beers • W. Zhao · S. H. Appel $(\bowtie)$ Department of Neurology, Houston Methodist Neurological Institute, Peggy and Gary Edwards ALS Research Laboratory, Houston Methodist Hospital Research Institute, Houston Methodist Hospital, Houston, TX 77030, USA

e-mail: sappel@tmhs.org

K. G. Hooten

Department of Neurological Surgery, University of Florida, Box 100265, Gainesville, FL 32610-0261, USA own therapeutic efforts are focused on modulating these neuroinflammatory pathways. This review will focus on the cellular players involved in neuroinflammation in ALS and current therapeutic strategies to enhance neuroprotection and suppress neurotoxicity with the goal of arresting the progressive and devastating nature of ALS.

Key Words ALS · amyotrophic lateral sclerosis . neuroinflammation $\cdot$ inflammation $\cdot$ neurodegenerative disease

\section{Overview of Motor Neuron Injury in Amyotrophic Lateral Sclerosis}

Amyotrophic lateral sclerosis (ALS) is the most prominent adult motor neuron disorder, affecting mostly motor neurons in the cerebral cortex, brainstem, and spinal cord [1]. Although first clinically described by Charcot in 1874, much of our understanding of the pathophysiology has occurred in the last 2 decades [2]. In 1993, the first genetic cause in ALS was identified, a point mutation in the gene encoding $\mathrm{Cu}^{2+}$ / $\mathrm{Zn}^{2+}$ superoxide dismutase (SOD1). The following year, the human cassette containing the G93A mutation of SOD1 (mSOD1) was inserted into a mouse [3-5]. Surprisingly, these mSOD1 transgenic mice developed a motor neuron disease similar to human ALS. Currently, $>150$ genetic mutations and $>20$ different genes have been identified that can lead to the same clinical disease of ALS in patients [6,7]. Thus, multiple mechanisms converge leading to inflammation and selective motor neuron death (Fig. 1).

The study of patients in combination with the ALS animal model has identified many complex molecular and cellular 


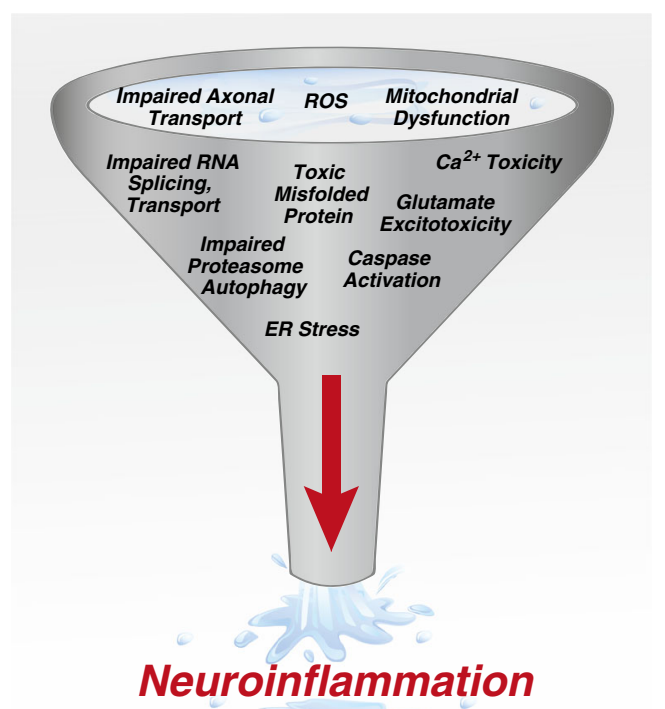

Fig. 1 Mechanisms of motor neuron injury. Motor neuron injury occurs in amyotrophic lateral sclerosis through both cell autonomous- and noncell-autonomous pathways. Multiple mechanisms can lead to motor neuron injury, which funnel into a final pathway or noncell-autonomous toxicity and neuroinflammation leading to motor neuron death

injurious pathways occurring peripherally at the neuromuscular junction and centrally at the cell body of the motor neuron [8-24]. Histopatholgy in the animal model reveals a disruption at the neuromuscular junction that appears first followed by a "dying back" of the axon [25]. Postmortem examination of ALS patient tissues reveals an obvious loss of motor neurons in the central nervous system (CNS), while many remaining neurons demonstrate central chromatolysis, numerous inclusions, swelling of the perikaryon and proximal axon, mitochondria swellings, vacuoles, and neurofilament accumulations [26]. Intracellular inclusions of ubiquitinated misfolded proteins, including transactive response DNA binding protein $43 \mathrm{kDa}$, SOD1, phosphorylated neurofiliaments, fused in sarcoma, and/or cystatin C occur in both hereditary and nonhereditary cases, and are a pathologic hallmark of disease [27-32]. The processes involved in motor neuron injury can be further categorized into mechanisms that are "cell autonomous" occurring within the motor neuron, and "noncell autonomous" involving multiple non-neuronal cells contributing to the disease process [33].

Evidence for immune and glial cells (i.e., noncellautonomous injury) affecting the fate of motor neurons comes from the mSOD1 transgenic mouse. In chimeric mice with selective expression of mSOD1 in motor neurons, an ALS phenotype either does not develop or develops very late in the life of the mouse [34-36]. Similarly, selective mSOD1 expression in non-neuronal cells also does not lead to the ALS phenotype, but motor neurons can develop signs of injury [37-40]. The addition of mSOD1-expressing astrocytes and microglial cells has been shown to accelerate disease progression, and wild-type microglia and astrocytes have been shown to slow disease [37, 39, 41, 42]. Other non-neuronal cells such as oligodendrocytes have also been shown to contribute to motor neuron injury, although through noninflammatory mechanisms [43-45]. To summarize the last 20 years of experimental manipulation of transgenic animals, ALS appears to be a multifactorial disease with many mechanisms leading to injury, but requiring non-neuronal cells for rapid disease progression and motor neuron death.

Much of the noncell-autonomous toxicity can be defined as "neuroinflammation". Once thought to be only a consequence of motor neuron death, neuroinflammation is now established as an important factor not only in the pathogenesis of ALS, but also in many other neurodegenerative diseases, including Parkinson's, Alzheimer's, multiple sclerosis, HIV-associated encephalopathy, and cerebrovascular disease [46-51]. Much of what has been learned in ALS regarding neuroinflammation has come through discoveries in these other neurodegenerative diseases. Neuroinflammation is now understood to contribute to the balance between neuroprotection and neurotoxicity. Evidence of the dual nature of inflammation in ALS exists in both human patients and animal models. During periods of slow disease progression, an anti-inflammatory process governs neuroinflammation. During periods of rapid progression, however, neuroinflammation is governed by a strong proinflammatory state. In this review, we discuss the key cellular players, the early neuroprotective phase (Fig. 2) and late injurious responses (Fig. 3), and potential treatment strategies to modulate these responses.

\section{Immune Cells Involved in the Neuroinflammation of ALS}

\section{Microglia}

Microglia are considered to be one of the first lines of defense for the CNS against injury and infection. As a component of the innate immune system, microglia colonize the CNS during early development to serve as the resident macrophages [39, 52]. Microglia, in addition to sampling the environment and presenting antigen, have patterned recognition receptors such as CD14 and Toll-like receptors (TLRs) 2 and 4, that when stimulated result in an innate immune response. These receptors have been suggested to be involved in multiple diverse neurodegenerative diseases [51, 53, 54]. Depending on the stimulus and surrounding cytokine milieu, microglia can be activated along a continuum with the ability to acquire a classically activated (M1) or alternatively activated (M2) phenotype [54-58]. In general, M1 promote a neurotoxic T-cell response and are cytotoxic owing to the secretion of reactive oxygen species (ROS) and proinflammatory cytokines, including interleukin (IL)-1, IL-6, and tumor necrosis factor (TNF)- $\alpha$, and a reduction in protective trophic factors 
Fig. 2 Neuroprotective phase of neuroinflammation. Initially in the disease course of amyotrophic lateral sclerosis, there is an early anti-inflammatory or

neuroprotective compensatory response of surrounding glia and immune cells. This early response is governed by T helper 2 cells (Th2)/regulatory T lymphocytes (Tregs), M2, and supportive astrocytes secreting neurotrophic factors and decreasing neuronal stress. GLT-1 = glutamate transporter; NTFs $=$ neurotrophic factors

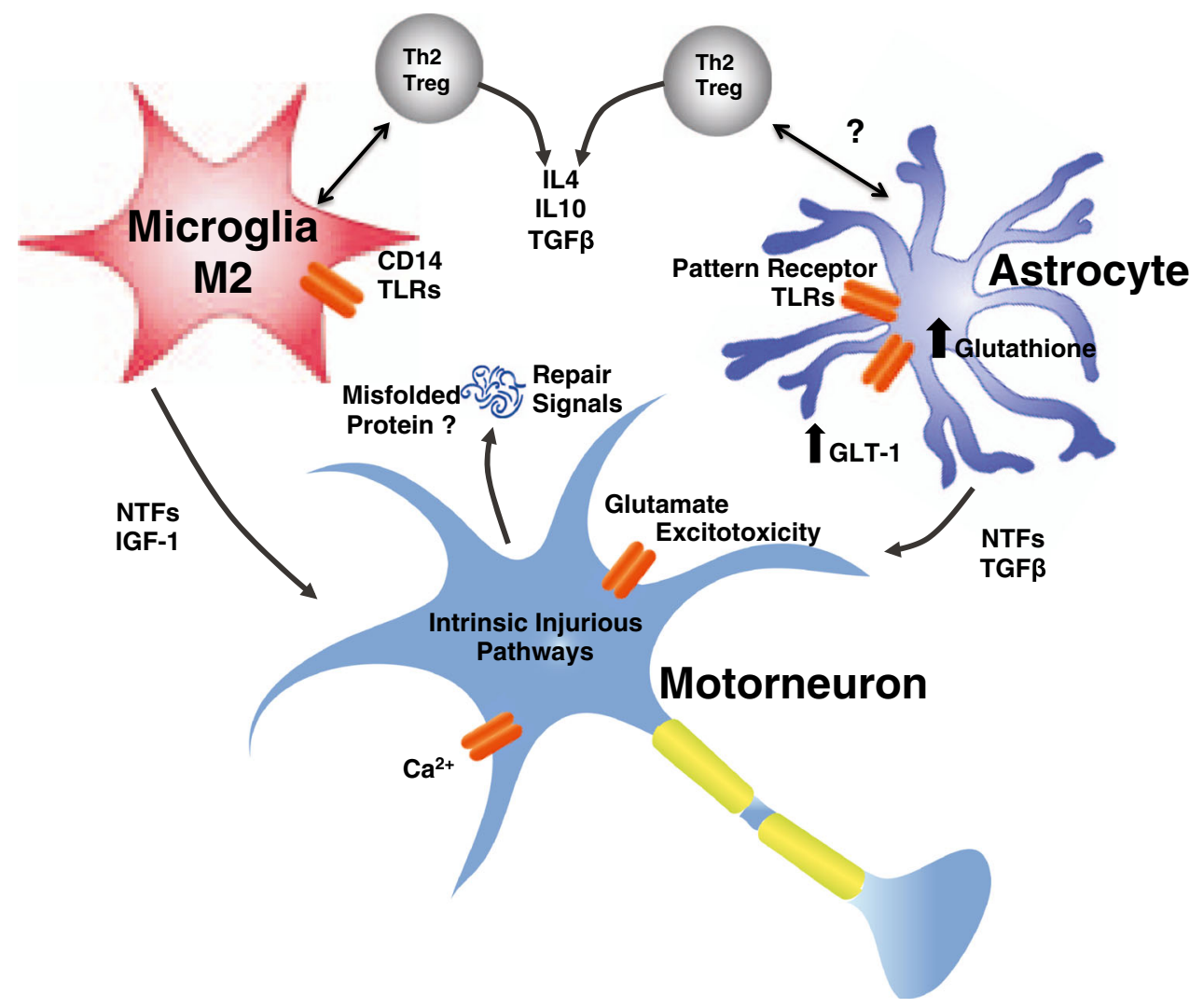

[59-63]. In contrast, M2 produce high levels of antiinflammatory cytokines and neurotrophic factors including IL-4, IL-10, and insulin-like growth factor (IGF)-1 in addition other neruoprotection signals such as CD200 and fractalkine [51, 60, 64-68].
In patients with ALS, microgliosis occurs specifically with motor neuron injury in the motor cortex, along the corticospinal tract, and in the ventral horn of the spinal cord [24, 53, 69-72]. Interestingly, positron emission tomography imaging, with either ${ }^{11} \mathrm{C}$-PK11195 or translocator protein
Fig. 3 Cytotoxic phase of neuroinflammation. Late in the course of the disease as the motor neuron becomes damaged, there is a transition from a neuroprotective response to an injurious response by the surrounding glia and immune cells. This is presumed to be a vicious cycle that starts when motor neuron death occurs inciting further inflammation and release of toxic factors

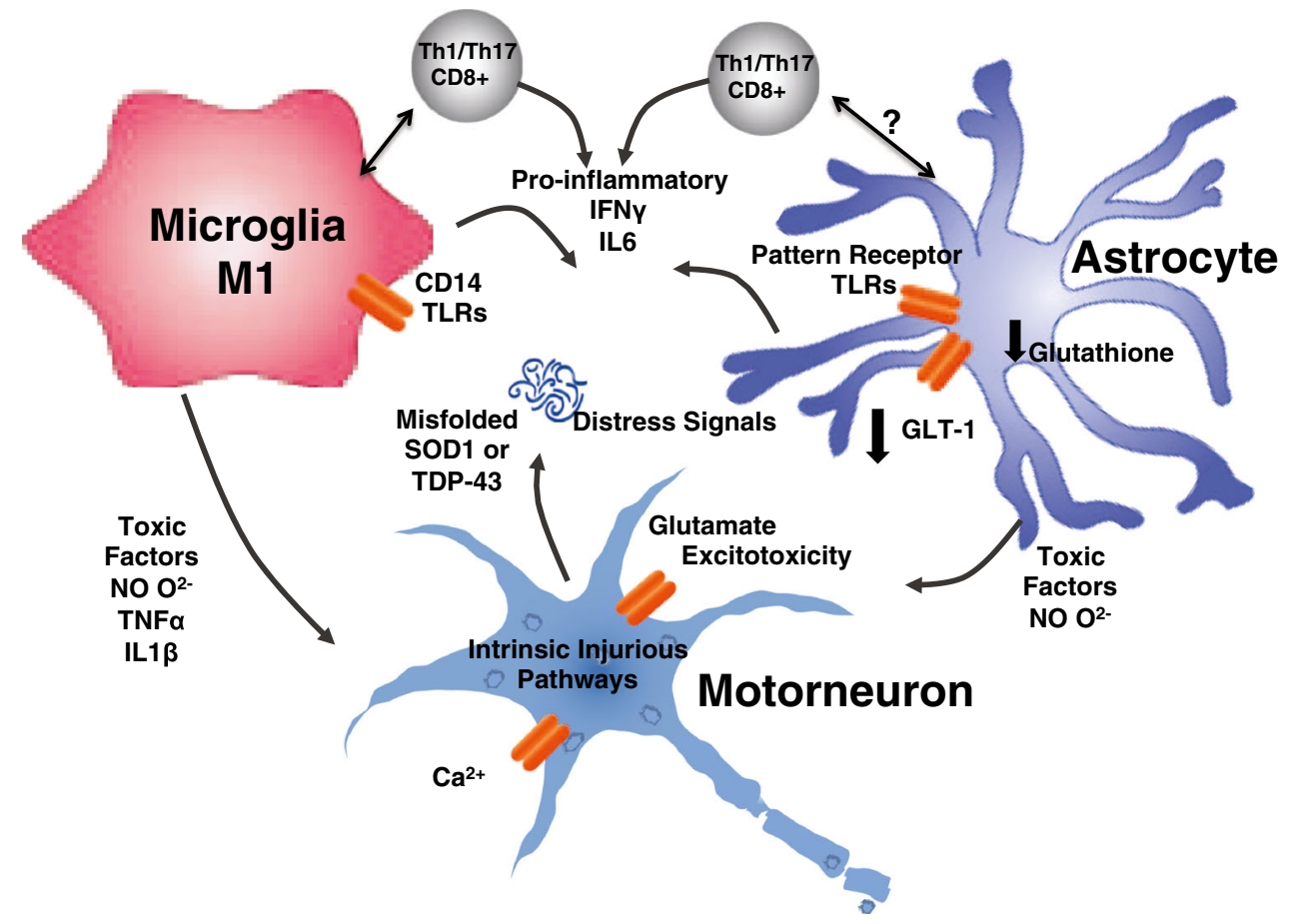


radioligands that bind microglia, has been used to image microglial activation corresponding with the location motor neuron injury in patients with ALS $[72,73]$. This radiographic evidence in humans correlates the with evidence in the G93A mSOD1 transgenic mouse, which demonstrates microglial activation even before motor neuron cell death $[74,75]$.

\section{Astroglia}

Astrocytes have many complex functions, including regulating extracellular neurotransmitter concentrations, exerting metabolic or ionic homeostatic function, providing structural and trophic support for neurons, and also contributing to the immune response [76, 77]. Astroglia contribute to motor neuron injury in both immune and nonimmune mechanisms. In patients with ALS and in animal models, astroglia have diminished expression of glutamate transporter-1 (excitatory amino-acid transporter-2), leading to glutamate excitotoxicity $[10,78,79]$. Astrocytes can also contribute to the immune response via pattern recognition receptors, including TLRs and mannose receptors. Following activation, astrocytes can secrete neurotoxic factors and cytokines, such as $\mathrm{C}-\mathrm{X}$-X motif chemokine 10, chemokine (C-C motif) ligand 2, and IL-6, greatly affecting the local environment $[24,40,53,76,80]$.

In patients with ALS, astrogliosis occurs more diffusely than microgliosis, occurring in the spinal cord as well as in the gray matter and subcortical white mater $[81,82]$. In the G93A mSOD1 transgenic mouse, activation of astrocytes occurs concomitantly with a decrease in motor neurons $[75,82$, 83]. Although astrocyte numbers increase with disease progression, astrocytes do not proliferate like microglia, but may be derived from ependymal cells lining the central canal of the spinal cord or oligodendrocyte precursor cells [24, 84-88].

\section{Additional Local Immune Cells}

Local dendritic cells (DCs) have been less well characterized, but also serve an important function in the disease process. DCs sample the local environment and present foreign antigens, and are increased in both human patients with ALS and in the mSOD1 transgenic mouse [89, 90]. During the course of disease, microglia/macrophages, DCs, and T cells contribute to the cytokine milieu that dictates the local neuroinflammatory response.

\section{T Lymphocytes}

$\mathrm{T}$ cells play an important role in governing acquired immune responses to diverse antigens. Specific T-cell subpopulations infiltrate the CNS during disease progression and contribute to the neuroinflammatory reaction in ALS [91-93]. In CNS tissues of both human patients with ALS and animal models, CD4+ T helper (Th) lymphocytes are observed in association with microglial activation, and cytotoxic $\mathrm{CD} 8+$ are observed in these tissues at later stages of disease [70, 93]. Several CD4+ subsets have been described, but most focus on 4 distinct subsets: Th1, Th2, Th17, and regulatory T lymphocytes (Tregs). Each subpopulation has specialized functions to control immune responses [94]. Like the classification of microglia/macrophages, CD4+ T cells can fall into 2 simplified classes: those that are neuroprotective (Th2 lymphocytes and Tregs), and those that are proinflammatory and neurotoxic (Th1 and Th17 lymphocytes). In 1995, Sakaguchi et al. [95] identified and described CD4+CD25+ immune suppressive cells with a role in self-tolerance. Tregs were then introduced to neurodegeneration with discoveries in multiple sclerosis $[96,97]$. Understanding the role of Tregs play in neurodegeneration has spread, encompassing many different neurodegenerative diseases, including ALS $[51,98]$. The role of Th17 is less well defined in the mSOD1 transgenic animal, but evidence from patients with ALS supports their involvement in the neuroinflammatory process [98-101].

\section{Additional Peripheral Immune Contributions}

Additional contributions from the peripheral immune system that have been investigated include the protein complement system, as well as peripheral monocytes/macrophages. Complement factors are mostly synthesized in the liver, but in mSOD1 transgenic animal models, complement factor $\mathrm{C} 1 \mathrm{q}$ transcription was noted to be upregulated in motor neurons [102]. However, the role of the complement pathway still remains controversial [103-106]. The role of peripheral monocytes in ALS is also controversial. Several authors suggest that peripheral monocytes infiltrate the ALS spinal cord contributing to motor neuron loss $[107,108]$. These results are inconsistent with previous parabiosis experiments that demonstrated no infiltration into the CNS from the periphery unless the blood-brain barrier was disrupted [84, 109-112]. However, monoctyes/macrophages have been demonstrated to aid in the inflammatory response of peripheral axons [113]. Additionally, immune system alterations, including decreased CD14+ monocytes early in the disease course, as well as evidence of monocyte activation in the blood, are documented in patients with ALS [114]. Further investigation is needed in both areas to define their contribution to neuroinflammation in ALS.

\section{Immune Cell Dialogue}

During periods of neuroinflammation, microglia acquire properties of antigen presenting cells such as CD11c, CD86, and intracellular adherin molecule 1, suggesting that these microglia interact closely with $T$ cells $[84,89,90,92]$. In vitro studies demonstrate that M2 cells have the ability to induce $\mathrm{CD} 4{ }^{+}$ 
Tregs with a strong suppressive anti-inflammatory function $[115,116]$. Similarly, CD4+ T cells cultured with M1 macrophages can produce a proinflammatory interferon (IFN)- $\gamma$ response [117]. $\mathrm{T}$ cells can also polarize microglia toward a M2 neuroprotective or a M1 cytotoxic phenotype depending on the type of T cell and cytokine milieu [67]. Additionally, all cytokine-producing cell types release factors that can influence activation states of the others [118-120]; chemokine (C$\mathrm{C}$ motif) ligand 2 and macrophage colony-stimulating factor are among other factors that are secreted by astrocytes and microglia in ALS [121]. It is thought that damaged motor neurons initiate the inflammatory response, although the exact mechanism is unknown. Potentially, mSOD1 released by motor neurons activate astrocytes and microglia via a TLR response [122, 123]. Intriguingly, mSOD1 has been demonstrated to transform and activate microglia to a M1 proinflammatory state, but mSOD1 also can induce a neuroprotective state with production of IGF-1 and progranulin secretion in certain conditions [53, 122, 124-127]. Both of these states can exist during the course of ALS and are determined by the cytokine milieu created in response to motor neuron injury.

\section{Early Neuroprotective Neuroinflammation Phase}

The initial belief regarding neuroinflammation in ALS was that all the cellular players represented a neurotoxic state. This idea was challenged after transfer of wild-type microglia slowed disease progression in the mSOD1 mouse [39]. Similarly, the view of T cells in ALS was changed by experiments that depleted the entire T-cell population by crossbreeding the mSOD1 transgenic mice with RAG2 ${ }^{-/-}$knockout or $\mathrm{TCR}^{-/-}$ knockout mice. Surprisingly, the disease course significantly worsened in these mSOD1 Tcell-deficient mice [92, 93]. Transfer of CD4+, and specifically Tregs, rescued these mice and extended survival $[93,128]$. Th2 CD4+ T cells and Tregs can express high levels of the anti-inflammatory factor IL-4, polarizing microglia to the neuroprotective (M2) phenotype [92]. Furthermore, these "neuroprotective" T cells may influence astroglial behavior by increasing their production of neurotrophic factors such as glial-cell-derived neurotrophic factor [93].

In the mSOD1 transgenic mouse, after disease onset, 2 clinical phases exists: An initial "slow" phase where the mouse does not appear to worsen clinically, followed by a "rapid" phase where the mouse declines clinically until euthanasia. In 2011, Beers et al. [98] demonstrated in the G93A mSOD1 transgenic mouse that during this initial "slow" phase M2 factors were predominant (Fig. 2). Also during this early phase, Th2/Tregs predominate with the secretion of IL-4, IL10 and other anti-inflammatory cytokines [98, 129]. Similarly, when Tregs were passively transferred into the ALS mouse, the "slow" phase and survival were prolonged [130].

\section{Late Neurotoxic Neuroinflammation Phase}

In the transgenic mSOD1 mouse, while the Tregs/M2 dialogue actively contributes to neuroprotection during the slow phase of the disease, a transformation occurs, and a rapid phase ensues with the concomitant injurious Th1/M1 response and Treg function suppression (Fig. 3) [98]. During the rapid disease course, proinflammatory and cytotoxic $\mathrm{T}$ cells predominate, contributing to the neurotoxic proinflammatory environment in conjunction with production of several cytokines, such as IL-1, IL-6, TNF- $\alpha$ and IFN- $\gamma$ [93, 98]. Overall, as the disease progresses, more Th1 cells are observed producing elevated levels of IFN- $\gamma$, which promotes M1 microglial activation. M1 cells can then promote proliferation and function of Th1/Th17 cells. This vicious cycle is believed to be a significant driving force for acceleration of disease course during the rapid phase.

\section{Neuroinflammation in Patients with ALS: Tregs}

Most importantly, many of these immune changes in the animal model have been confirmed in patients with nonhereditary ALS [24, 70, 99, 100, 131, 132]. Henkel et al. [133] demonstrated that in patients with rapidly progressing clinical states, an inverse correlation was seen between Treg numbers in the blood and leukocyte levels of FoxP3, a transcription factor required for Treg suppressive function [134]. In a second cohort of patients with ALS, the decreased cell numbers and decreased FoxP3 expression were $80 \%$ sensitive in predicting rapid progression in patients with ALS. After 3.5 years, $35 \%$ of patients with ALS with decreased FoxP3 levels were deceased or ventilator dependent, while only $13 \%$ of patients with ALS with increased FoxP3 levels were deceased or ventilator dependent. Factors that are elevated during the later period that can inhibit the suppressive ability of Tregs include TNF- $\alpha$, IL- $1 \beta$, and IL- 6 . TNF- $\alpha$ has been demonstrated to inhibit the phosphorylation of FoxP3 [135]. IL-1 $\beta$ was required to drive the conversion of Tregs to IL17producing cells [136]. IL-6 has been reported to inhibit the generation of FoxP3+ Tregs [137]. Interestingly, anti-IL-6 treatment through toclilizumab has shown suggestive clinical benefit and is currently being tested in patients with ALS [138]. Clearly, understanding the interactions between peripheral and central immune responses will be essential in any attempt to manipulate the disease via neuroinflammatory mechanisms.

\section{ALS Immunomodulation Treatment Strategies}

In the last decade, neuroinflammation has been documented to contribute to the pathogenesis of motor neuron injury in 
transgenic ALS mouse models. No therapy that appeared promising in transgenic ALS mice, including many targeting neuroinflammation, has improved clinical outcomes in patients with ALS. It is clear that the mouse model has a more homogenous disease phenotype compared with the heterogeneous clinical disease in patients; humans are not just big mice. Multiple factors provide insight as to why translation of therapeutic benefit from mouse to human has failed, including the lack of data delineating the extensive cytokine milieu created in response to motor neuron injury. In mSOD1 transgenic mice, decreasing or deleting single proinflammatory factors such as TNF- $\alpha$, IL1- $\beta$, and inducible nitric oxide synthase has had little-to-no effect on overall survival [139-141]. Clearly, the multiplicity of proinflammatory cytokines can compensate for the absence of any single factor, and it is unlikely that continuing efforts to target a single factor will provide significant therapeutic benefit in patients with ALS.

Drugs targeting neuroinflammation such as celecoxib, ceftriaxone, thalidomide, and minocycline were reported to enhance survival in transgenic mice, yet none were effective in human ALS trials [142-144]. Some critics have suggested suboptimal animal study design such as inadequate powering or administration of drug to mice prior to onset of signs of disease, while in patients with ALS administration can only begin well after the appearance of disease symptoms and signs $[145,146]$. Similarly, targeting the downstream effect of ROS has shown benefit in ALS animal models but not in patients with ALS [147]. Immunosuppressive drugs such as glucocorticoids, cyclophosphamide, azathioprine, and cyclosporine, among others, that have proven efficacy in diverse immunological disorders have not shown efficacy in ALS $[148,149]$. If neuroinflammation is an appropriate therapeutic target in ALS, we must ask why these immunomodulatory medications have failed in clinical trials. Is it too little too late? Is neuroinflammation a meaningful therapeutic target only in a small population of the diverse ALS phenotypes? Or is it possible that these therapies failed to hit the appropriate targets? Unfortunately, in most studies, neither the appropriate target is defined nor is there evidence that the therapies actually hit the putative target.

The lack of translation of therapeutic benefit in transgenic mouse models to patients with ALS underscores at least 2 complicating factors: the significant heterogeneity of disease in patients with ALS, and the lack of biomarkers to differentiate patients with ALS with slowly progressing disease from those with rapidly progressing disease. In mSOD 1 transgenic mice, early slowly progressing disease can be readily differentiated from later rapidly progressing disease; the spinal cords of the former are characterized by increased protective Tregs and M2 microglia/macrophages, while the spinal cords of the latter are characterized by decreased Tregs and increased Th1 lymphocytes and M1 microglia/macrophages. However, in the heterogeneous population of patients with ALS enrolled in any study, populations of patients progressing rapidly are intermixed with patients progressing slowly. Even though neuroprotecitve immune factors may be present in the spinal cord in early disease and neurotoxic immune factors in later disease in patients with ALS, readily available access to spinal cords, disease heterogeneity, and an inability to separate slow from fast progression significantly limit therapeutic benefit. In the absence of the ability to separate fast from slow progressors, or the presence of an admixture of neuroprotective and neurotoxic cellular immunity, therapeutic efforts may need to simultaneously downregulate proinflammatory cellular immunity and upregulate antiinflammatory cellular immunity.

One potential target and treatment strategy would be to decrease the signals activating the inflammatory response. This approach includes the use of interfering RNA to decrease production of misfolded toxic proteins. These techniques have lead to success and positive results in animal models $[150,151]$. Currently, this approach is being translated in the clinic to patients with ALS; however, no long-term outcome data have been published [152]. There is concern, though, that once the vicious, irreversible proinflammatory cycle begins, this approach may not be successful.

To modulate effectively neuroinflammation in ALS, the studies in transgenic mice suggest potential targets that are not modulated by present-day anti-inflammatory or immunosuppressive therapies. During early stages of disease in the mSOD1 mouse, microglia are neuroprotective (M2), while in later, rapidly progressive stages of disease microglia are cytotoxic (M1). T lymphocytes are similarly neuroprotective early in disease (Th2/Tregs) and neurotoxic later in disease (Th1/ Th17). Therapies that target all populations of $\mathrm{T}$ lymphocytes, including Tregs, Th2, Th1, and Th17 cells, would simultaneously suppress both protective and cytotoxic populations. Thus, potentially effective therapies would need to enhance protective $\mathrm{T}$ cells (Tregs/Th2) and/or suppress cytotoxic T cells (Th1/Th17), but suppressing both populations simultaneously would not change the balance between pro- and anti-inflammatory responses, and might not promote beneficial effects. Similar therapeutic strategies targeting microglia or monocyte/macrophage populations should preferably attempt to enhance microglial M2 responses and suppress microglial-mediated M1reponses simultaneously.

The successful transfer of Tregs into ALS mice to upregulate neuroprotective pathways and downregulate cytoxic pathways makes therapies targeting Tregs attractive. Passive transfer of Tregs has become an effective clinical therapy in graftversus-host disease $[153,154]$. Treatment with cytokines and 
growth factors such as IL-2, granulocyte macrophage colonystimulating factor, or IGF-1 have been shown to increase Tregs reliably in other diseases [155-157]. Epigenetic modification of FOXP3 is also under investigation for potential treatment opportunities [158]. Future therapies in ALS involving Tregs may incorporate all these approaches to tip the balance back towards neuroprotection. One significant caution in Treg therapy is the potential of these cells to be converted to Th17 proinflammatory cells in the presence of the increased proinflammatory cytokine milieu, which may promote disease progression.

Other cellular based therapies targeting immune cells are also under investigation. Early attempts with CD34 hematopoietic stem cell transplantation were not successful at enhancing survival or suppressing the neuroinflammatory responses within the spinal cord, for reasons mentioned above [159]. However, transplantation of mesenchymal stem cells has had promising results in animal models, and early-phase trials in patients with ALS are in progress [160]. In these later studies, the goal is not to replace the injured motor neuron, but to use these stem cells as a Trojan Horse to deliver growth factors to repair motor neurons and thereby halt disease progression. Another cell-based therapy to repair injured motor neurons is to inject embryonic stem cells directly into the spinal cord of patients with ALS; to date, 18 patients with ALS have been implanted and are being carefully monitored [161, 162].

Another approach to suppressing neuroinflammation would be to decrease the population of M1 monocyte/ macrophages and enhance the population of M2 monocyte/ macrophages. Similar to Tregs, passive transfer may be an option. Transfer or M2 microglia/macrophages has been shown to be an effective treatment in experimental autoimmune encephalitis [116]. Already in clinical trial, NP001, a novel immunomodulator of proinflmmatory monocyte/macrophages, appeared to suppress neuroinflammation and slow progression in ALS, but these results await a larger confirmatory study [163].

\section{Conclusions}

Effective therapy of ALS remains in its infancy, even after many years of intense investigation and discovery. As highlighted throughout this review, the pathways involved in motor neuron death in ALS are complex, with diverse cellular and molecular contributions leading to motor neuron injury and eventual neuronal death. Neuroinflammation in neurodegenerative disease has evolved from what was once thought as a secondary effect or consequence of neuron injury to being accepted as making a key contribution to motor neuron pathophysiology and disease propagation. In ALS, the fact that mutations in different genes can result in common clinical manifestations of ALS, as well as the fact that neurons do not die on their own, suggest that neuroinflammation is a common denominator and necessary to induce neurodegeneration in ALS.

Despite the complexity, disease progression in ALS that eventually leads to motor neuron death can be divided into 2 phases. The first phase is cell autonomous, with motor neuron injury mediated by many mechanisms summarized in Fig. 1. During this early phase of slow disease progression, data gleaned from both human and animal models suggest that the immune system is neuroprotective with glia and $\mathrm{T}$ cells, especially M2 macrophages/microglia and Tregs, providing factors that sustain motor neuron viability (Fig. 2). As the disease progresses and the intrinsic motor neuron autonomous injury proceeds and accumulates, and the extrinsic noncell-autonomous repair processes fail and a second rapidly progressing phase ensues characterized by M1 macrophages/microglia, and Th1 and Th17 T cells. Although the signals emitted from motor neurons triggering both an injurious innate immune glia and adaptive immune T-cell response have not been fully elucidated, current data suggest that the neuroprotective M2/Treg/Th2-mediated pathways are downregulated and the cytotoxic M1/Th1/Th17 pathways are upregulated, resulting in a self-propagating proinflammatory acceleration of disease progression. The nature of these signals remains unknown, but the misfolded proteins themselves, such as SOD1 and transactive response DNA binding protein $43 \mathrm{kDa}$, or peptide fragments may mediate an M1/Th1/Th17 proinflammatory cascade leading to the precipitous demise of the motor neuron. Such neuroinflammation may not initiate neuronal injury, but amplify and propagate the injury instigated by the motor neuron-emitted "danger signals".

Despite many studies defining the multiple intraneuronal pathways compromised in ALS, no therapies have provided meaningful benefits to patients with ALS. Current data suggest that cell-based therapies aimed at affecting and modulating the neuroinflammatory responses in ALS might provide these therapeutic benefits. Tregs are especially attractive as a potential therapy as the passive transfer of Tregs in the mSOD1 mouse model of ALS demonstrated clinical improvement and prolonged survival. Alternative therapies include compounds that can maintain the early microglial M2 phenotype and other compounds that transform the late microglial M1 phenotype into a protective M2 phenotype. Thus, a focus on cell-based therapies aimed at modulating the neuroinflammatory response in ALS, including the specific signals involved in the microglial-T-cell dialogue, may help arrest the progressive and devastating nature of this disease, and provide hope for patients with ALS. 
Required Author Forms Disclosure forms provided by the authors are available with the online version of this article.

\section{References}

1. Kiernan MC, Vucic S, Cheah BC, et al. Amyotrophic lateral sclerosis. Lancet 2011;377:942-955.

2. Zinman L, Cudkowicz M. Emerging targets and treatments in amyotrophic lateral sclerosis. Lancet Neurol 2011;10:481-490.

3. Rosen DR. Mutations in $\mathrm{Cu} / \mathrm{Zn}$ superoxide dismutase gene are associated with familial amyotrophic lateral sclerosis. Nature 1993;364:362.

4. Rosen DR, Siddique T, Patterson D, et al. Mutations in $\mathrm{Cu} / \mathrm{Zn}$ superoxide dismutase gene are associated with familial amyotrophic lateral sclerosis. Nature 1993;362:59-62.

5. Gurney ME, Pu H, Chiu AY, et al. Motor neuron degeneration in mice that express a human $\mathrm{Cu}, \mathrm{Zn}$ superoxide dismutase mutation. Science 1994;264:1772-1775.

6. Tortelli R, Conforti FL, Cortese R, et al. Amyotrophic lateral sclerosis: a new missense mutation in the SOD1 gene. Neurobiol Aging 2013;34:1709.

7. Renton AE, Chio A, Traynor BJ. State of play in amyotrophic lateral sclerosis genetics. Nat Neurosci 2014;17:17-23.

8. Ferraiuolo L, Kirby J, Grierson AJ, Sendtner M, Shaw PJ. Molecular pathways of motor neuron injury in amyotrophic lateral sclerosis. Nat Rev Neurol 2011;7:616-630.

9. Vucic S, Kiernan MC. Cortical excitability testing distinguishes Kennedy's disease from amyotrophic lateral sclerosis. Clin Neurophysiol 2008;119:1088-1096.

10. Rothstein JD, Martin LJ, Kuncl RW. Decreased glutamate transport by the brain and spinal cord in amyotrophic lateral sclerosis. N Engl J Med 1992;326:1464-1468.

11. Mackenzie IR, Rademakers R, Neumann M. TDP-43 and FUS in amyotrophic lateral sclerosis and frontotemporal dementia. Lancet Neurol 2010;9:995-1007.

12. Winkler EA, Sengillo JD, Sagare AP, et al. Blood-spinal cord barrier disruption contributes to early motor-neuron degeneration in ALSmodel mice. Proc Natl Acad Sci U S A 2014;111:E1035-E1042.

13. Damiano M, Starkov AA, Petri S, et al. Neural mitochondrial Ca2+ capacity impairment precedes the onset of motor symptoms in G93A Cu/Zn-superoxide dismutase mutant mice. J Neurochem 2006;96:1349-1361.

14. Liu J, Lillo C, Jonsson PA, et al. Toxicity of familial ALS-linked SOD1 mutants from selective recruitment to spinal mitochondria. Neuron 2004;43:5-17.

15. Vande Velde C, Miller TM, Cashman NR, Cleveland DW. Selective association of misfolded ALS-linked mutant SOD1 with the cytoplasmic face of mitochondria. Proc Natl Acad Sci U S A 2008;105: 4022-4027.

16. Sathasivam S, Grierson AJ, Shaw PJ. Characterization of the caspase cascade in a cell culture model of SOD1-related familial amyotrophic lateral sclerosis: expression, activation and therapeutic effects of inhibition. Neuropathol Appl Neurobiol 2005;31: 467-485.

17. Sathasivam S, Shaw PJ. Apoptosis in amyotrophic lateral sclerosis what is the evidence? Lancet Neurol 2005;4:500-509.

18. Wiedemann FR, Manfredi G, Mawrin C, Beal MF, Schon EA. Mitochondrial DNA and respiratory chain function in spinal cords of ALS patients. J Neurochem 2002;80:616-625.

19. Blackburn D, Sargsyan S, Monk PN, Shaw PJ. Astrocyte function and role in motor neuron disease: a future therapeutic target? Glia 2009;57:1251-1264.
20. Duffy LM, Chapman AL, Shaw PJ, Grierson AJ. Review: The role of mitochondria in the pathogenesis of amyotrophic lateral sclerosis. Neuropathol Appl Neurobiol 2011;37:336-352.

21. Rao SD, Weiss JH. Excitotoxic and oxidative cross-talk between motor neurons and glia in ALS pathogenesis. Trends Neurosci 2004;27:17-23.

22. Sargsyan SA, Monk PN, Shaw PJ. Microglia as potential contributors to motor neuron injury in amyotrophic lateral sclerosis. Glia 2005;51:241-253.

23. Wood JD, Beaujeux TP, Shaw PJ. Protein aggregation in motor neurone disorders. Neuropathol Appl Neurobiol 2003;29:529-545.

24. Ackerley S, Grierson AJ, Brownlees J, et al. Glutamate slows axonal transport of neurofilaments in transfected neurons. J Cell Biol 2000;150:165-176.

25. Fischer LR, Culver DG, Tennant $P$, et al. Amyotrophic lateral sclerosis is a distal axonopathy: evidence in mice and man. Exp Neurol 2004;185:232-240.

26. Martin LJ. Neuronal death in amyotrophic lateral sclerosis is apoptosis: possible contribution of a programmed cell death mechanism. J Neuropathol Exp Neurol 1999;58:459-471.

27. Piao YS, Wakabayashi K, Kakita A, et al. Neuropathology with clinical correlations of sporadic amyotrophic lateral sclerosis: 102 autopsy cases examined between 1962 and 2000. Brain Pathol 2003; 13:10-22.

28. Ince PG, Tomkins J, Slade JY, Thatcher NM, Shaw PJ. Amyotrophic lateral sclerosis associated with genetic abnormalities in the gene encoding $\mathrm{Cu} / \mathrm{Zn}$ superoxide dismutase: molecular pathology of five new cases, and comparison with previous reports and 73 sporadic cases of ALS. J Neuropathol Exp Neurol 1998;57: 895-904.

29. Neumann M, Sampathu DM, Kwong LK, et al. Ubiquitinated TDP43 in frontotemporal lobar degeneration and amyotrophic lateral sclerosis. Science 2006;314:130-133.

30. Shibata N, Hirano A, Kobayashi M, et al. $\mathrm{Cu} / \mathrm{Zn}$ superoxide dismutase-like immunoreactivity in Lewy body-like inclusions of sporadic amyotrophic lateral sclerosis. Neurosci Lett 1994;179: 149-152.

31. Groen EJ, van Es MA, van Vught PW, et al. FUS mutations in familial amyotrophic lateral sclerosis in the Netherlands. Arch Neurol 2010;67:224-230.

32. Gruzman A, Wood WL, Alpert E, et al. Common molecular signature in SOD1 for both sporadic and familial amyotrophic lateral sclerosis. Proc Natl Acad Sci U S A 2007;104:12524-12529.

33. Ilieva H, Polymenidou M, Cleveland DW. Non-cell autonomous toxicity in neurodegenerative disorders: ALS and beyond. J Cell Biol 2009;187:761-772.

34. Pramatarova A, Laganiere J, Roussel J, Brisebois K, Rouleau GA. Neuron-specific expression of mutant superoxide dismutase 1 in transgenic mice does not lead to motor impairment. J Neurosci 2001;21:3369-3374.

35. Lino MM, Schneider C, Caroni P. Accumulation of SOD1 mutants in postnatal motoneurons does not cause motoneuron pathology or motoneuron disease. J Neurosci 2002;22:48254832.

36. Jaarsma D, Teuling E, Haasdijk ED, De Zeeuw CI, Hoogenraad CC. Neuron-specific expression of mutant superoxide dismutase is sufficient to induce amyotrophic lateral sclerosis in transgenic mice. $\mathrm{J}$ Neurosci 2008;28:2075-2088.

37. Yamanaka K, Chun SJ, Boillee S, et al. Astrocytes as determinants of disease progression in inherited amyotrophic lateral sclerosis. Nat Neurosci 2008;11:251-253.

38. Gong YH, Parsadanian AS, Andreeva A, Snider WD, Elliott JL. Restricted expression of G86R $\mathrm{Cu} / \mathrm{Zn}$ superoxide dismutase in astrocytes results in astrocytosis but does not cause motoneuron degeneration. J Neurosci 2000;20:660-665. 
39. Beers DR, Henkel JS, Xiao Q, et al. Wild-type microglia extend survival in PU.1 knockout mice with familial amyotrophic lateral sclerosis. Proc Natl Acad Sci U S A 2006;103:16021-16026.

40. Nagai M, Re DB, Nagata T, et al. Astrocytes expressing ALS-linked mutated SOD1 release factors selectively toxic to motor neurons. Nat Neurosci 2007;10:615-622.

41. Yamanaka K, Boillee S, Roberts EA, et al. Mutant SOD1 in cell types other than motor neurons and oligodendrocytes accelerates onset of disease in ALS mice. Proc Natl Acad Sci U S A 2008;105: 7594-7599.

42. Clement AM, Nguyen MD, Roberts EA, et al. Wild-type nonneuronal cells extend survival of SOD1 mutant motor neurons in ALS mice. Science 2003;302:113-117.

43. Kang SH, Li Y, Fukaya M, et al. Degeneration and impaired regeneration of gray matter oligodendrocytes in amyotrophic lateral sclerosis. Nat Neurosci 2013;16:571-579.

44. Lee Y, Morrison BM, Li Y, et al. Oligodendroglia metabolically support axons and contribute to neurodegeneration. Nature 2012;487:443-448.

45. Philips T, Bento-Abreu A, Nonneman A, et al. Oligodendrocyte dysfunction in the pathogenesis of amyotrophic lateral sclerosis. Brain 2013; 136:471-482.

46. Gonzalez H, Elgueta D, Montoya A, Pacheco R. Neuroimmune regulation of microglial activity involved in neuroinflammation and neurodegenerative diseases. J Neuroimmunol 2014;274:1-13.

47. More SV, Kumar H, Kim IS, Song SY, Choi DK. Cellular and molecular mediators of neuroinflammation in the pathogenesis of Parkinson's disease. Mediators Inflamm 2013;2013: 952375.

48. Obulesu M, Jhansilakshmi M. Neuroinflammation in Alzheimer's disease: an understanding of physiology and pathology. Int $\mathrm{J}$ Neurosci 2014;124:227-235.

49. Zhao W, Beers DR, Appel SH. Immune-mediated mechanisms in the pathoprogression of amyotrophic lateral sclerosis. J Neuroimmune Pharmacol 2013;8:888-899.

50. He F, Balling R. The role of regulatory T cells in neurodegenerative diseases. Wiley Interdiscip Rev Syst Biol Med 2013;5:153-180.

51. Gendelman HE, Appel SH. Neuroprotective activities of regulatory T cells. Trends Mol Med 2011;17:687-688.

52. McKercher SR, Torbett BE, Anderson KL, et al. Targeted disruption of the PU.1 gene results in multiple hematopoietic abnormalities. EMBO J 1996; 15:5647-5658

53. Philips T, Robberecht W. Neuroinflammation in amyotrophic lateral sclerosis: role of glial activation in motor neuron disease. Lancet Neurol 2011;10:253-263.

54. Zhao J, Brooks DM, Lurie DI. Lipopolysaccharide-activated SHP1-deficient motheaten microglia release increased nitric oxide, TNFalpha, and IL-1beta. Glia 2006;53:304-312.

55. Hanisch UK, Kettenmann H. Microglia: active sensor and versatile effector cells in the normal and pathologic brain. Nat Neurosci 2007;10:1387-1394.

56. Kreutzberg GW. Microglia: a sensor for pathological events in the CNS. Trends Neurosci 1996;19:312-318.

57. Ransohoff RM, Perry VH. Microglial physiology: unique stimuli, specialized responses. Annu Rev Immunol 2009;27:119-145.

58. Zhao W, Xie W, Xiao Q, Beers DR, Appel SH. Protective effects of an anti-inflammatory cytokine, interleukin-4, on motoneuron toxicity induced by activated microglia. J Neurochem 2006;99: 1176-1187.

59. Ebert S, Schoeberl T, Walczak Y, et al. Chondroitin sulfate disaccharide stimulates microglia to adopt a novel regulatory phenotype. J Leukoc Biol 2008;84:736-740.

60. Komohara Y, Ohnishi K, Kuratsu J, Takeya M. Possible involvement of the M2 anti-inflammatory macrophage phenotype in growth of human gliomas. J Pathol 2008;216:15-24.

61. Michelucci A, Heurtaux T, Grandbarbe L, Morga E, Heuschling P. Characterization of the microglial phenotype under specific pro- inflammatory and anti-inflammatory conditions: Effects of oligomeric and fibrillar amyloid-beta. J Neuroimmunol 2009;210:3-12.

62. Smith JA, Das A, Ray SK, Banik NL. Role of pro-inflammatory cytokines released from microglia in neurodegenerative diseases. Brain Res Bull 2012;87:10-20.

63. Boche D, Perry VH, Nicoll JA. Review: activation patterns of microglia and their identification in the human brain. Neuropathol Appl Neurobiol 2013;39:3-18.

64. Ferreira R, Lively S, Schlichter LC. IL-4 type 1 receptor signaling up-regulates KCNN4 expression, and increases the KCa3.1 current and its contribution to migration of alternative-activated microglia. Front Cell Neurosci 2014;8:183.

65. Cherry JD, Olschowka JA, O'Banion MK. Neuroinflammation and M2 microglia: the good, the bad, and the inflamed. J Neuroinflamm 2014;11:98.

66. Crain JM, Nikodemova M, Watters JJ. Microglia express distinct M1 and M2 phenotypic markers in the postnatal and adult central nervous system in male and female mice. J Neurosci Res 2013;91: 1143-1151.

67. Appel SH, Beers DR, Henkel JS. T cell-microglial dialogue in Parkinson's disease and amyotrophic lateral sclerosis: are we listening? Trends Immunol 2010;31:7-17.

68. Cardona AE, Pioro EP, Sasse ME, et al. Control of microglial neurotoxicity by the fractalkine receptor. Nat Neurosci 2006;9: 917-924.

69. Engelhardt JI, Appel SH. IgG reactivity in the spinal cord and motor cortex in amyotrophic lateral sclerosis. Arch Neurol 1990;47:12101216.

70. Engelhardt JI, Tajti J, Appel SH. Lymphocytic infiltrates in the spinal cord in amyotrophic lateral sclerosis. Arch Neurol 1993;50: 30-36.

71. Kawamata T, Akiyama H, Yamada T, McGeer PL. Immunologic reactions in amyotrophic lateral sclerosis brain and spinal cord tissue. Am J Pathol 1992;140:691-707.

72. Turner MR, Cagnin A, Turkheimer FE, et al. Evidence of widespread cerebral microglial activation in amyotrophic lateral sclerosis: an $[11 \mathrm{C}](\mathrm{R})-\mathrm{PK} 11195$ positron emission tomography study. Neurobiol Dis 2004;15:601-609.

73. Corcia P, Tauber C, Vercoullie J, et al. Molecular imaging of microglial activation in amyotrophic lateral sclerosis. PLOS ONE 2012;7:e52941.

74. Alexianu ME, Kozovska M, Appel SH. Immune reactivity in a mouse model of familial ALS correlates with disease progression. Neurology 2001;57:1282-1289.

75. Hall ED, Oostveen JA, Gurney ME. Relationship of microglial and astrocytic activation to disease onset and progression in a transgenic model of familial ALS. Glia 1998;23:249-256.

76. Farina C, Aloisi F, Meinl E. Astrocytes are active players in cerebral innate immunity. Trends Immunol 2007;28:138-145.

77. Sofroniew MV, Vinters HV. Astrocytes: biology and pathology. Acta Neuropathol 2010;119:7-35.

78. Medina L, Figueredo-Cardenas G, Rothstein JD, Reiner A. Differential abundance of glutamate transporter subtypes in amyotrophic lateral sclerosis (ALS)-vulnerable versus ALS-resistant brain stem motor cell groups. Exp Neurol 1996;142:287-295.

79. Rothstein JD, Dykes-Hoberg M, Pardo CA, et al. Knockout of glutamate transporters reveals a major role for astroglial transport in excitotoxicity and clearance of glutamate. Neuron 1996;16: 675-686.

80. Di Giorgio FP, Carrasco MA, Siao MC, Maniatis T, Eggan K. Noncell autonomous effect of glia on motor neurons in an embryonic stem cell-based ALS model. Nat Neurosci 2007;10:608-614.

81. Nagy D, Kato T, Kushner PD. Reactive astrocytes are widespread in the cortical gray matter of amyotrophic lateral sclerosis. J Neurosci Res 1994;38:336-347. 
82. Schiffer D, Cordera S, Cavalla P, Migheli A. Reactive astrogliosis of the spinal cord in amyotrophic lateral sclerosis. J Neurol Sci 1996;139(Suppl.):27-33.

83. Levine JB, Kong J, Nadler M, Xu Z. Astrocytes interact intimately with degenerating motor neurons in mouse amyotrophic lateral sclerosis (ALS). Glia 1999;28:215-224.

84. Gowing G, Philips T, Van Wijmeersch B, et al. Ablation of proliferating microglia does not affect motor neuron degeneration in amyotrophic lateral sclerosis caused by mutant superoxide dismutase. J Neurosci 2008;28:10234-10244.

85. Lepore AC, Dejea C, Carmen J, et al. Selective ablation of proliferating astrocytes does not affect disease outcome in either acute or chronic models of motor neuron degeneration. Exp Neurol 2008;211:423-432.

86. Rivers LE, Young KM, Rizzi M, et al. PDGFRA/NG2 glia generate myelinating oligodendrocytes and piriform projection neurons in adult mice. Nat Neurosci 2008;11:1392-1401.

87. Zhu X, Bergles DE, Nishiyama A. NG2 cells generate both oligodendrocytes and gray matter astrocytes. Development 2008;135: 145-157.

88. Zhu X, Hill RA, Nishiyama A. NG2 cells generate oligodendrocytes and gray matter astrocytes in the spinal cord. Neuron Glia Biol 2008;4:19-26.

89. Henkel JS, Beers DR, Siklos L, Appel SH. The chemokine MCP-1 and the dendritic and myeloid cells it attracts are increased in the mSOD1 mouse model of ALS. Mol Cell Neurosci 2006;31:427-437.

90. Henkel JS, Engelhardt JI, Siklos L, et al. Presence of dendritic cells, MCP-1, and activated microglia/macrophages in amyotrophic lateral sclerosis spinal cord tissue. Ann Neurol 2004;55:221-235.

91. McGeer PL, McGeer EG. Inflammatory processes in amyotrophic lateral sclerosis. Muscle Nerve 2002;26:459-470.

92. Chiu IM, Chen A, Zheng Y, et al. T lymphocytes potentiate endogenous neuroprotective inflammation in a mouse model of ALS. Proc Natl Acad Sci U S A 2008;105:17913-17918.

93. Beers DR, Henkel JS, Zhao W, Wang J, Appel SH. CD4+ T cells support glial neuroprotection, slow disease progression, and modify glial morphology in an animal model of inherited ALS. Proc Natl Acad Sci U S A 2008;105:15558-15563.

94. Romagnani S. T cell subpopulations. Chem Immunol Allergy 2014;100:155-164

95. Sakaguchi S, Sakaguchi N, Asano M, Itoh M, Toda M. Immunologic self-tolerance maintained by activated $\mathrm{T}$ cells expressing IL-2 receptor alpha-chains (CD25). Breakdown of a single mechanism of self-tolerance causes various autoimmune diseases. J Immunol 1995;155:1151-1164.

96. Viglietta V, Baecher-Allan C, Weiner HL, Hafler DA. Loss of functional suppression by $\mathrm{CD} 4+\mathrm{CD} 25+$ regulatory $\mathrm{T}$ cells in patients with multiple sclerosis. J Exp Med 2004;199:971-979.

97. Kohm AP, Carpentier PA, Anger HA, Miller SD. Cutting edge: $\mathrm{CD} 4+\mathrm{CD} 25+$ regulatory $\mathrm{T}$ cells suppress antigen-specific autoreactive immune responses and central nervous system inflammation during active experimental autoimmune encephalomyelitis. J Immunol 2002;169:4712-4716.

98. Beers DR, Henkel JS, Zhao W, et al. Endogenous regulatory T lymphocytes ameliorate amyotrophic lateral sclerosis in mice and correlate with disease progression in patients with amyotrophic lateral sclerosis. Brain 2011;134:1293-1314.

99. Rentzos M, Rombos A, Nikolaou C, et al. Interleukin-17 and interleukin-23 are elevated in serum and cerebrospinal fluid of patients with ALS: a reflection of Th17 cells activation? Acta Neurol Scand 2010;122:425-429.

100. Fiala M, Chattopadhay M, La Cava A, et al. IL-17A is increased in the serum and in spinal cord CD8 and mast cells of ALS patients. $\mathrm{J}$ Neuroinflamm 2010;7:76.

101. Saresella M, Piancone F, Tortorella P, et al. T helper-17 activation dominates the immunologic milieu of both amyotrophic lateral sclerosis and progressive multiple sclerosis. Clin Immunol 2013;148:79-88.

102. Woodruff TM, Costantini KJ, Taylor SM, Noakes PG. Role of complement in motor neuron disease: animal models and therapeutic potential of complement inhibitors. Adv Exp Med Biol 2008; 632:143-158.

103. Lobsiger CS, Boillee S, Pozniak C, et al. C1q induction and global complement pathway activation do not contribute to ALS toxicity in mutant SOD1 mice. Proc Natl Acad Sci U S A 2013;110:E4385E4392.

104. Lobsiger CS, Cleveland DW. Reply to Woodruff et al.: C1q and C3dependent complement pathway activation does not contribute to disease in SOD1 mutant ALS mice. Proc Natl Acad Sci U S A 2014;111:E5.

105. Woodruff TM, Costantini KJ, Crane JW, et al. The complement factor C5a contributes to pathology in a rat model of amyotrophic lateral sclerosis. J Immunol 2008;181:8727-8734.

106. Woodruff TM, Lee JD, Noakes PG. Role for terminal complement activation in amyotrophic lateral sclerosis disease progression. Proc Natl Acad Sci U S A 2014;111:E3-E4.

107. Butovsky O, Siddiqui S, Gabriely G, et al. Modulating inflammatory monocytes with a unique microRNA gene signature ameliorates murine ALS. J Clin Invest 2012;122:3063-3087.

108. Ohnishi S, Ito H, Suzuki Y, et al. Intra-bone marrow-bone marrow transplantation slows disease progression and prolongs survival in G93A mutant SOD1 transgenic mice, an animal model mouse for amyotrophic lateral sclerosis. Brain Res 2009;1296:216-224.

109. Solomon JN, Lewis CA, Ajami B, Corbel SY, Rossi FM, Krieger C. Origin and distribution of bone marrow-derived cells in the central nervous system in a mouse model of amyotrophic lateral sclerosis. Glia 2006;53:744-753.

110. Ajami B, Bennett JL, Krieger C, McNagny KM, Rossi FM. Infiltrating monocytes trigger EAE progression, but do not contribute to the resident microglia pool. Nat Neurosci 2011;14:1142-1149.

111. Ajami B, Bennett JL, Krieger C, Tetzlaff W, Rossi FM. Local selfrenewal can sustain CNS microglia maintenance and function throughout adult life. Nat Neurosci 2007;10:1538-1543.

112. Chiu IM, Morimoto ET, Goodarzi H, et al. A neurodegenerationspecific gene-expression signature of acutely isolated microglia from an amyotrophic lateral sclerosis mouse model. Cell Rep 2013;4:385-401.

113. Kano O, Beers DR, Henkel JS, Appel SH. Peripheral nerve inflammation in ALS mice: cause or consequence. Neurology 2012;78: 833-835.

114. Mantovani S, Garbelli S, Pasini A, et al. Immune system alterations in sporadic amyotrophic lateral sclerosis patients suggest an ongoing neuroinflammatory process. J Neuroimmunol 2009;210:73-79.

115. Savage ND, de Boer T, Walburg KV, et al. Human antiinflammatory macrophages induce Foxp3+ GITR+CD25+ regulatory $\mathrm{T}$ cells, which suppress via membrane-bound TGFbeta-1. J Immunol 2008;181:2220-2226.

116. Zhang XM, Lund H, Mia S, Parsa R, Harris RA. Adoptive transfer of cytokine-induced immunomodulatory adult microglia attenuates experimental autoimmune encephalomyelitis in DBA/1 mice. Glia 2014;62:804-817.

117. Martinez FO, Sica A, Mantovani A, Locati M. Macrophage activation and polarization. Front Biosci 2008;13:453-461.

118. Boillee S, Vande Velde C, Cleveland DW. ALS: a disease of motor neurons and their nonneuronal neighbors. Neuron 2006;52:39-59.

119. Boillee S, Yamanaka K, Lobsiger CS, et al. Onset and progression in inherited ALS determined by motor neurons and microglia. Science 2006;312:1389-1392.

120. Wang L, Gutmann DH, Roos RP. Astrocyte loss of mutant SOD1 delays ALS disease onset and progression in G85R transgenic mice. Hum Mol Genet 2011;20:286-293. 
121. Gowing G, Lalancette-Hebert M, Audet JN, Dequen F, Julien JP. Macrophage colony stimulating factor (M-CSF) exacerbates ALS disease in a mouse model through altered responses of microglia expressing mutant superoxide dismutase. Exp Neurol 2009;220:267-275.

122. Zhao W, Beers DR, Henkel JS, et al. Extracellular mutant SOD1 induces microglial-mediated motoneuron injury. Glia 2010;58:231-243.

123. Urushitani M, Sik A, Sakurai T, Nukina N, Takahashi R, Julien JP. Chromogranin-mediated secretion of mutant superoxide dismutase proteins linked to amyotrophic lateral sclerosis. Nat Neurosci 2006;9:108-118

124. Meissner F, Molawi K, Zychlinsky A. Mutant superoxide dismutase 1-induced IL-1 beta accelerates ALS pathogenesis. Proc Natl Acad Sci U S A 2010;107:13046-13050.

125. Weydt P, Yuen EC, Ransom BR, Moller T. Increased cytotoxic potential of microglia from ALS-transgenic mice. Glia 2004;48: 179-182.

126. Philips T, De Muynck L, Thu HN, et al. Microglial upregulation of progranulin as a marker of motor neuron degeneration. $\mathrm{J}$ Neuropathol Exp Neurol 2010;69:1191-1200.

127. Van Damme P, Van Hoecke A, Lambrechts D, et al. Progranulin functions as a neurotrophic factor to regulate neurite outgrowth and enhance neuronal survival. J Cell Biol 2008;181:37-41.

128. Banerjee R, Mosley RL, Reynolds AD, et al. Adaptive immune neuroprotection in G93A-SOD1 amyotrophic lateral sclerosis mice. PLOS ONE 2008; 3:e2740.

129. Tiemessen MM, Jagger AL, Evans HG, van Herwijnen MJ, John S, Taams LS. CD4+CD25+Foxp3+ regulatory T cells induce alternative activation of human monocytes/macrophages. Proc Natl Acad Sci U S A 2007;104:19446-19451.

130. Zhao W, Beers DR, Liao B, Henkel JS, Appel SH. Regulatory T lymphocytes from ALS mice suppress microglia and effector $\mathrm{T}$ lymphocytes through different cytokine-mediated mechanisms. Neurobiol Dis 2012;48:418-428.

131. Graves MC, Fiala M, Dinglasan LA, et al. Inflammation in amyotrophic lateral sclerosis spinal cord and brain is mediated by activated macrophages, mast cells and T cells. Amyotroph Lateral Scler Other Motor Neuron Disord 2004;5:213-219.

132. Liu G, Fiala M, Mizwicki MT, et al. Neuronal phagocytosis by inflammatory macrophages in ALS spinal cord: inhibition of inflammation by resolvin D1. Am J Neurodegener Dis 2012;1:60-74.

133. Henkel JS, Beers DR, Wen S, et al. Regulatory T-lymphocytes mediate amyotrophic lateral sclerosis progression and survival. EMBO Mol Med 2013;5:64-79.

134. Rentzos M, Evangelopoulos E, Sereti E, et al. Alterations of T cell subsets in ALS: a systemic immune activation? Acta Neurol Scand 2012;125:260-264.

135. Nie H, Zheng Y, Li R, et al. Phosphorylation of FOXP3 controls regulatory $\mathrm{T}$ cell function and is inhibited by TNF-alpha in rheumatoid arthritis. Nat Med 2013;19:322-328.

136. Li L, Kim J, Boussiotis VA. IL-1beta-mediated signals preferentially drive conversion of regulatory $\mathrm{T}$ cells but not conventional T cells into IL-17-producing cells. J Immunol 2010;185:4148-4153.

137. Bettelli E, Carrier Y, Gao W, et al. Reciprocal developmental pathways for the generation of pathogenic effector TH17 and regulatory T cells. Nature 2006;441:235-238.

138. Mizwicki MT, Fiala M, Magpantay L, et al. Tocilizumab attenuates inflammation in ALS patients through inhibition of IL6 receptor signaling. Am J Neurodegener Dis 2012;1:305-315.

139. Gowing G, Dequen F, Soucy G, Julien JP. Absence of tumor necrosis factor-alpha does not affect motor neuron disease caused by superoxide dismutase 1 mutations. J Neurosci 2006;26:11397-11402.

140. Nguyen MD, Julien JP, Rivest S. Induction of proinflammatory molecules in mice with amyotrophic lateral sclerosis: no requirement for proapoptotic interleukin-1beta in neurodegeneration. Ann Neurol 2001;50:630-639.
141. Son M, Fathallah-Shaykh HM, Elliott JL. Survival in a transgenic model of FALS is independent of iNOS expression. Ann Neurol 2001;50:273.

142. Cudkowicz ME, Shefner JM, Schoenfeld DA, et al. Trial of celecoxib in amyotrophic lateral sclerosis. Ann Neurol 2006;60:22-31.

143. Mitsumoto H, Brooks BR, Silani V. Clinical trials in amyotrophic lateral sclerosis: why so many negative trials and how can trials be improved? Lancet Neurol 2014;13:1127-1138.

144. Goyal NA, Mozaffar T. Experimental trials in amyotrophic lateral sclerosis: a review of recently completed, ongoing and planned trials using existing and novel drugs. Exp Opin Invest Drugs 2014;23: 1541-1551.

145. Scott S, Kranz JE, Cole J, et al. Design, power, and interpretation of studies in the standard murine model of ALS. Amyotroph Lateral Scler 2008;9:4-15.

146. Perrin S. Preclinical research: Make mouse studies work. Nature 2014;507:423-425.

147. Orrell RW, Lane RJ, Ross M. A systematic review of antioxidant treatment for amyotrophic lateral sclerosis/motor neuron disease. Amyotroph Lateral Scler 2008;9:195-211.

148. Smith SA, Miller RG, Murphy JR, Ringel SP. Treatment of ALS with high dose pulse cyclophosphamide. J Neurol Sci 1994;124(Suppl.):84-87.

149. Werdelin L, Boysen G, Jensen TS, Mogensen P. Immunosuppressive treatment of patients with amyotrophic lateral sclerosis. Acta Neurol Scand 1990;82:132-134.

150. Foust KD, Salazar DL, Likhite S et al. Therapeutic AAV9-mediated suppression of mutant SOD1 slows disease progression and extends survival in models of inherited ALS. Mol Ther 2013;21:2148-2159.

151. Ralph GS, Radcliffe PA, Day DM, et al. Silencing mutant SOD1 using RNAi protects against neurodegeneration and extends survival in an ALS model. Nat Med 2005;11:429-433.

152. Miller TM, Pestronk A, David W, et al. An antisense oligonucleotide against SOD1 delivered intrathecally for patients with SOD1 familial amyotrophic lateral sclerosis: a phase 1, randomised, firstin-man study. Lancet Neurol 2013;12:435-442.

153. Veerapathran A, Pidala J, Beato F, et al. Human regulatory T cells against minor histocompatibility antigens: ex vivo expansion for prevention of graft-versus-host disease. Blood 2013;122: 2251-2261.

154. Trzonkowski P, Bieniaszewska M, Juscinska J, et al. First-in-man clinical results of the treatment of patients with graft versus host disease with human ex vivo expanded CD4+CD25+CD127- T regulatory cells. Clin Immunol 2009;133:22-26.

155. Kosloski LM, Kosmacek EA, Olson KE, Mosley RL, Gendelman HE. GM-CSF induces neuroprotective and anti-inflammatory responses in 1-methyl-4-phenyl-1,2,3,6-tetrahydropyridine intoxicated mice. J Neuroimmunol 2013;265:1-10.

156. Bilbao D, Luciani L, Johannesson B, Piszczek A, Rosenthal N. Insulin-like growth factor-1 stimulates regulatory T cells and suppresses autoimmune disease. EMBO Mol Med 2014;6:1423-1435.

157. Kosmaczewska A. Low-dose interleukin-2 therapy: A driver of an imbalance between immune tolerance and autoimmunity. Int J Mol Sci 2014;15:18574-18592.

158. Toker A, Engelbert D, Garg G, et al. Active demethylation of the Foxp3 locus leads to the generation of stable regulatory $\mathrm{T}$ cells within the thymus. J Immunol 2013;190:3180-3188.

159. Appel SH, Engelhardt JI, Henkel JS, et al. Hematopoietic stem cell transplantation in patients with sporadic amyotrophic lateral sclerosis. Neurology 2008;71:1326-1334.

160. Mazzini L, Vercelli A, Ferrero I, Boido M, Cantello R, Fagioli F. Transplantation of mesenchymal stem cells in ALS. Prog Brain Res 2012;201:333-359.

161. Feldman EL, Boulis NM, Hur J, et al. Intraspinal neural stem cell transplantation in amyotrophic lateral sclerosis: phase 1 trial outcomes. Ann Neurol 2014;75:363-373. 
162. Glass JD, Boulis NM, Johe K, et al. Lumbar intraspinal injection of neural stem cells in patients with amyotrophic lateral sclerosis: results of a phase I trial in 12 patients. Stem Cells 2012;30: 1144-1151.
163. Miller RG, Zhang R, Block G, et al. NP001 regulation of macrophage activation markers in ALS: A phase I clinical and biomarker study. Amyotroph Lateral Scler Frontotemporal Degener 2014;15: 601-609. 